\title{
The Impact of Environmental Variables on UAS-based Atmospheric Carbon Dioxide Measurements
}

\author{
Gustavo B. H. de Azevedo*1,2, Bill Doyle ${ }^{2}$, Christopher A. Fiebrich ${ }^{3}$, and David Schvartzman ${ }^{1}$ \\ ${ }^{1}$ Advanced Radar Research Center (ARRC) at The University of Oklahoma \\ ${ }^{2}$ Center for Autonomous Sensing and Sampling (CASS) at The University of Oklahoma \\ ${ }^{3}$ Oklahoma Mesonet, Oklahoma Climatological Survey at The University of Oklahoma
}

Correspondence: Gustavo B. H. de Azevedo (gust@ou.edu)

\begin{abstract}
This article assesses the individual impact of pressure, temperature, and humidity on the accuracy of atmospheric $\mathrm{CO}_{2}$ measurements collected by Unmanned Aerial Systems (UAS) using low-cost commercial Non-Dispersive Infrared sensors (NDIR). We build upon previous experimental results in the literature and systematically increase the variation range for each environmental variable to match the abrupt changes found in UAS vertical profiles. As a key contribution, we present a lowcost benchtop correction procedure to mitigate the impact of these variables and considerably improve the accuracy of $\mathrm{CO}_{2}$ measurements to be within $\pm 2.5 \mathrm{ppm}$. Our findings support the use of low-cost NDIR sensors for UAS-based atmospheric $\mathrm{CO}_{2}$ measurements as a complementary in-situ tool for many scientific applications.
\end{abstract}

\section{Introduction}

Over the past 60 years, atmospheric Carbon Dioxide $\left(\mathrm{CO}_{2}\right)$ has been measured with instrumented towers, satellites, and manned aircraft. During this period, these measurement systems provided insight into global concentration trends, continental fluxes, and other large scale behaviors (Kunz et al., 2018). In recent years atmospheric $\mathrm{CO}_{2}$ studies have shifted focus from global and continental scales to finer regional and local scales (i.e., mesoscale, $2 \mathrm{~m}$ to $20 \mathrm{~km}$, minutes to hours, Stephens et al., 2011). These new regional studies demonstrated how the mentioned measurement systems do not always support fast and comprehensive data collection near regional and local phenomena. Over the past two decades, Unmanned Aerial Systems (UAS) have grown as a complementary in-situ observation tool for local atmospheric $\mathrm{CO}_{2}$ profiles (Villa et al., 2016). This growth is justified by the relatively low cost of UAS and its ability to provide atmospheric $\mathrm{CO}_{2}$ measurements with high spatiotemporal resolution (Piedrahita et al., 2014). In a literature survey, Villa et al. (2016) also highlights other motivations, such as in-situ validation of remote instruments, autonomous plume tracking, and locating hazardous emission sources.

${ }^{*}$ Gustavo B. H. de Azevedo is now with the Unmanned Systems Research Institute at Oklahoma State University (OSU). Email: gus@okstate.edu 

cation's feasibility (Nelson et al., 2019; Cartier, 2019; Kunz et al., 2018; Martin et al., 2017; Mitchell et al., 2016; Kiefer et al., 2012; Yasuda et al., 2008; Watai et al., 2006). In addition, the size, weight, and power requirements of sensors are also critical to the design of UAS-based solutions (Martin et al., 2017). For these reasons, many UAS-based atmospheric $\mathrm{CO}_{2}$ measurement systems use commercial low-cost Non-Dispersive Infrared (NDIR) sensors (B. H. de Azevedo, 2020; Kunz et al., 2018; Martin et al., 2017; Gibson and MacGregor, 2013; Stephens et al., 2011; Yasuda et al., 2008; Pandey and Kim, 2007; Watai et al., 2006; Chen et al., 2002). However, abrupt changes in pressure, temperature, and humidity associated with atmospheric vertical profiles can interfere with NDIR sensors.

In this article, we begin by briefly reviewing the main concerns regarding the use of commercial low-cost NDIR sensors for atmospheric $\mathrm{CO}_{2}$ measurements found in the literature. We then build upon previous experimental results in the literature by investigating the impact of each environmental variable on the measured $\mathrm{CO}_{2}$ while systematically increasing their absolute values. Finally, we evaluate the performance of a low-cost NDIR sensor under a wide range of conditions. As a key contribution of this article, we propose a set of low-cost benchtop procedures that can be used to characterize and mitigate the impact of these variables on the same sensor. We believe these low-cost procedures can be used by the scientific community to improve the accuracy of UAS-based $\mathrm{CO}_{2}$ measurements and increase assimilation of UAS-based $\mathrm{CO}_{2}$ datasets by atmospheric scientists.

\subsection{Background}

Many low-cost NDIR-based $\mathrm{CO}_{2}$ sensors are available in the international market (Tab. A1 lists a few examples with some basic specifications). Besides the attractive low cost, most of these sensors are light and have low power requirements. However, as shown in Tab. A1, the errors reported by their manufacturers are larger than what might be measured as the maximum concentration variation when performing an atmospheric vertical profile. To mitigate this accuracy issue, some researchers investigated methods to characterize and correct them in post-processing (Ashraf et al., 2018; Martin et al., 2017; Gaynullin et al., 2016; Yasuda et al., 2012; Mizoguchi and Ohtani, 2005). In some cases, accuracy was improved from $\pm 30 \mathrm{ppm}$ to \pm 1.9 ppm (Martin et al., 2017). However, according to Kunz et al. (2018), the improvements achieved by Martin et al. (2017); Piedrahita et al. (2014); Yasuda et al. (2012); Mizoguchi and Ohtani (2005) are not applicable to UAS-based sampling due to the stronger rates of change in pressure, temperature, and humidity associated with UAS profiles.

Another issue that arises when using low-cost NDIR-based $\mathrm{CO}_{2}$ sensors for atmospheric measurements is their uncertain sample diffusion time. None of the sensors available in the market was designed for UAS-based deployment. Therefore, their optical chambers assume a natural air exchange with the environment over a long period (minutes to hours). This design characteristic creates an artificially slow time response. To mitigate this issue, some manufactures offer optional airflow intakes for the sensors (e.g., CO2Meter's pump cap for the K30), and some researchers design custom sensor housings to control airflow and integrate the sensors into the aircraft. These custom sensor housings, such as the one designed by B. H. de Azevedo (2020), can improve the sensor time response from $30 \mathrm{~s}$ to approximately $1 \mathrm{~s}$ (under $0.5 \mathrm{Ls}^{-1}$ flow). However, it is important to note that spatiotemporal results from systems using this technique are averaged and assume some degree of spatiotemporal homogeneity. Therefore, their use in some plume tracking applications, amongst others, is limited. 
As mentioned previously, changes in pressure, temperature, and humidity can interfere with NDIR sensors. Even though some studies have addressed the impact of environmental variables on these sensors, they have done so through lumped correction methods (e.g., multivariate linear regression analysis in Martin et al., 2017). These lumped approaches limit the understanding of the individual impact of each variable, and are not robust for wide variation ranges. These limitations may prevent system developers from addressing measurement requirements during the sensor package design phase (e.g., heat shielding), thus creating more issues to be corrected in post-processing. To address this limitation, we increased the experimental conditions of the previous characterization procedures found in the literature to adequate them to UAS flight conditions. We also isolated the effects of pressure, temperature, and relative humidity on an NDIR sensor and analyzed their impact separately. More information about the experiments is given in sections 3 through 6.

\section{Methodology}

Due to the large number of low-cost NDIR-based $\mathrm{CO}_{2}$ sensors available and the unfeasibility of evaluating all of them, we searched the literature for model comparison studies and the rate of adoption of each model. We used this methodology to select a model that would represent the current state of the art for low-cost UAS-based atmospheric $\mathrm{CO}_{2}$ sampling. In a comparison study, Yasuda et al. (2012) evaluated five different models and concluded the Senseair $\mathrm{K}_{30} \mathrm{NDIR} \mathrm{CO}_{2}$ sensor offered the best combination of cost, weight, and accuracy between models considered. A similar result was found by Al-Hajjaji et al. (2017), who compared five other sensors to the K30.

The adoption of the K30 for UAS-based measurements was compared to the adoption of other models by their use in the reviewed literature. The adoption of these sensor models in the literature was evaluated through a search on the GoogleScholar ${ }^{\mathrm{TM}}$ database. This search followed the method from the literature review on UAS-based gas sampling done by Villa et al. (2016). The list of search terms and resulting analysis can be found in Tab. B1. The analysis suggests that the K30 is more prevalent in the literature than the other models tested by Yasuda et al. (2012) and Al-Hajjaji et al. (2017). For these reasons, all experiments in this article were performed with the Senseair $\mathrm{K} 30 \mathrm{NDIR} \mathrm{CO}_{2}$ sensor.

To evaluate the individual impact of pressure, temperature, and humidity on low-cost NDIR sensors, we performed two sets of experiments. The first set was performed at the Oklahoma Mesonet Calibration Laboratory to explore each variable's impact at more extensive variation ranges. The environmental chambers of the Oklahoma Mesonet Calibration Laboratory allow great control over each variable, creating appropriate conditions to simulate UAS flights. A description of the Oklahoma Mesonet and its facilities can be found in McPherson et al. (2007). The second set of experiments was performed on a regular laboratory workbench. These experiments were designed to expand the results from the first set of experiments and evaluate the feasibility of deriving correction coefficients from low-cost experiments. Details for each experiment and results are given in sections 3 through 6.

All experiments in this article were performed using two units of the Senseair K30-FR NDIR $\mathrm{CO}_{2}$ sensor under $0.5 \mathrm{Ls}^{-1}$ airflow. This strategy was adopted to increase the confidence in the results obtained and evaluate considerations found in the literature regarding the need for distinct correction coefficients for each sensor unit. Finally, it is important to note that all 
results and analyses in this article considered only the $\mathrm{CO}_{2}$ concentration values reported by each sensor unit. In other words, each unit was assumed to be immutable from its factory-performed calibration. Therefore, no attempts were made to analyze and correct the light absorption signals within the K30. Instead, each sensor unit was evaluated and corrected as a "black-box". This method was adopted to evaluate if these sensors could produce satisfactory results only with post-processing techniques.

\section{Temperature dependence}

The temperature dependence experiment performed at the Oklahoma Mesonet Calibration Laboratory used the Thunder Scientific 2500 chamber to produce a temperature variation from $10{ }^{\circ} \mathrm{C}$ to $40{ }^{\circ} \mathrm{C}$, in ten-degree increments, at a constant $50 \% \mathrm{RH}$. Each temperature change was followed by a two-hour dwell period. Even though the temperature and humidity are controlled, this chamber is not entirely isolated from the external environment. This means the experiment was executed at the atmospheric pressure conditions for the day in Oklahoma, and the changes in $\mathrm{CO}_{2}$ concentration in the laboratory could affect the experiment. To mitigate contamination, access to the laboratory was limited during the experiment, but not interrupted. To corroborate the results and evaluate possible contamination, reference gas analyzers were placed inside and outside the chamber. Fig. 1 illustrates the sensor arrangement for this experiment.

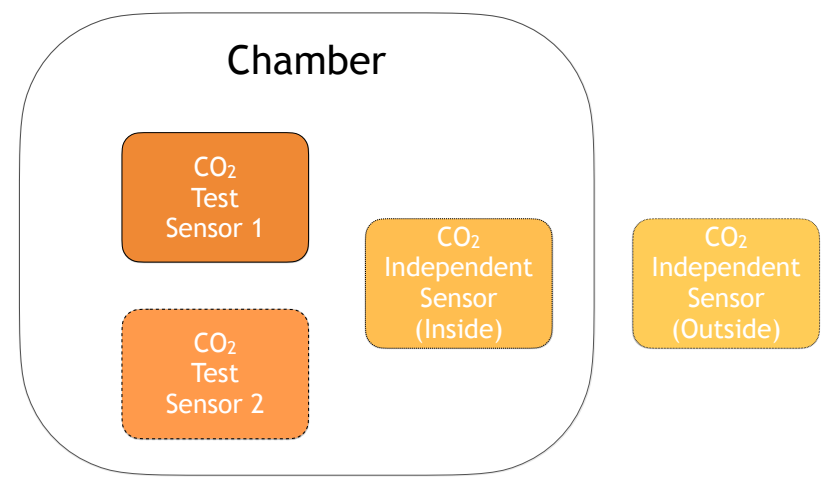

Figure 1. Experiment diagram for temperature and relative humidity at the Oklahoma Mesonet Calibration Laboratory. Two test sensors were placed inside the chamber with a control sensor, and a reference sensor was placed outside to detect possible contamination.

The reference gas analyzer inside the chamber was the LI-COR LI-840A. This sensor served as a control because LI-840A is also a light-based sensor, but it uses sample conditioning to eliminate interference from pressure, temperature, and humidity. The LI-840A heats the sampled air to $60{ }^{\circ} \mathrm{C}$ before measuring its $\mathrm{CO}_{2}$ concentration. Therefore, the variation from $10{ }^{\circ} \mathrm{C}$ to $40{ }^{\circ} \mathrm{C}$ inside the chamber does not affect its measurements. The gas analyzer outside the chamber was the LI-COR LI-820. 
This analyzer served as a reference for the experiment conditions within the laboratory. For these reasons, in this article, the

LI-840A and the LI-820 are referred to as independent sensor (inside) and independent sensor (outside), respectively.

The results for the Mesonet temperature dependence experiment are shown here in two formats. The first format, in Fig. 2, shows the time series for the chamber's temperature and the reported concentrations for all four $\mathrm{CO}_{2}$ sensors. The second format, in Fig. 3, shows the scatter plots and correlation coefficients for all six comparisons between the test sensors, test variable, and reference sensors.

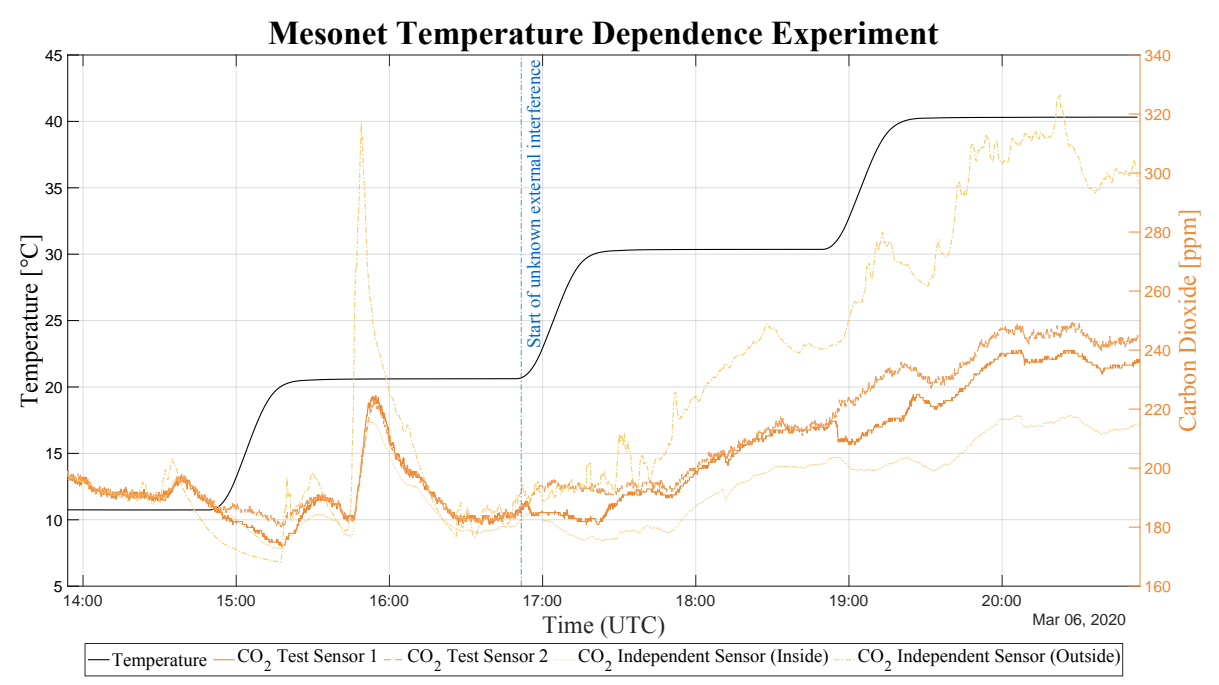

Figure 2. Time-series data for the Mesonet temperature dependence experiment. The solid black curve represents the temperature inside the chamber. The orange curves represent the $\mathrm{CO}_{2}$ concentrations reported by the independent and test sensors. The black (left) and orange (right) $\mathrm{y}$-axes provide the scales for temperature and $\mathrm{CO}_{2}$ measurements, respectively.

Analyzing the time-series data for the experiment, there only seems to be an increase in $\mathrm{CO}_{2}$ when the temperature increases from $20{ }^{\circ} \mathrm{C}$ to $30{ }^{\circ} \mathrm{C}$ and from $30{ }^{\circ} \mathrm{C}$ to $40{ }^{\circ} \mathrm{C}$. However, this $\mathrm{CO}_{2}$ increase is also observed more than one hour after each temperature change, during the dwell periods for $30{ }^{\circ} \mathrm{C}$ and $40{ }^{\circ} \mathrm{C}$. Furthermore, similar $\mathrm{CO}_{2}$ increases are also observed on the internal and external independent sensors. This leads us to believe the experiment was contaminated by an increase in concentration in the laboratory. This hypothesis is supported by the stronger correlations between the test sensors and the independent sensors than the correlations between the test sensors and temperature.

Further analyzing the correlation between temperature and the test sensors, we note a change in behavior around the 16:51 timestamp. Before this timestamp, the correlation coefficient between temperature and test sensors was -0.18 (for sensor 1) and 0.04 (for sensor 2). After this timestamp, both coefficients increase ( 0.86 and 0.92 , respectively). This increase coincides with the sudden increase in the reported concentration outside the test chamber. We cannot find evidence to support temperature dependence when evaluating the temperature correlation coefficients during the temperature changes (summarized in Tab. 1).

To rule out any minor temperature dependence effects obscured by the interference on the Mesonet experiment, a second experiment was performed focused on the temperature change from $20^{\circ} \mathrm{C}$ and $40{ }^{\circ} \mathrm{C}$. This second experiment was performed 


\section{Correlation Coefficients for the Mesonet Experiment}

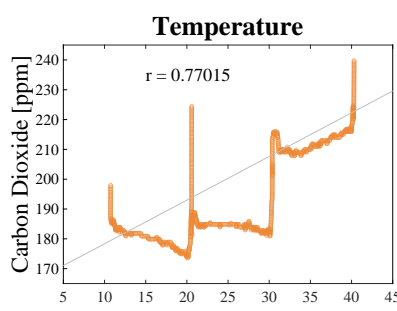
$\mathrm{CO}_{2}$ Independent Sensor

$\mathrm{CO}_{2}$ Independent Sensor
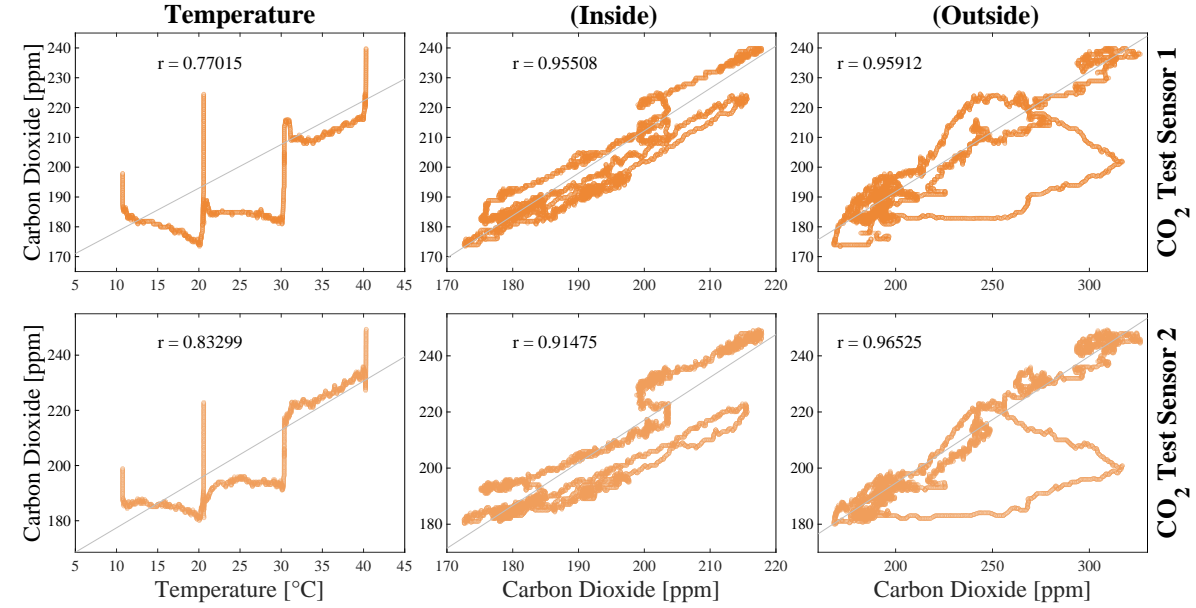

Figure 3. Scatter plots and correlation coefficients for the Mesonet temperature dependence experiments. The first row shows the correlations for Test Sensor 1. The second row shows the correlations for Test Sensor 2. The first column shows the correlations with temperature, the second column with the Independent Sensor (inside), and the third column with the Independent Sensor (outside).

Table 1. $\mathrm{CO}_{2}$ correlation coefficient for each test sensor, for each temperature change, during the Mesonet temperature dependence experiment.

\begin{tabular}{ccc} 
Temperature $\left[{ }^{\circ} \mathbf{C}\right]$ & \multicolumn{2}{c}{ Correlation coefficient } \\
& Sensor 1 & Sensor 2 \\
\hline From 10 to 20 & -0.97 & -0.80 \\
From 20 to 30 & -0.81 & 0.64 \\
From 30 to 40 & 0.58 & 0.97 \\
\hline
\end{tabular}

as a low-cost benchtop experiment, with the two test sensors and the LI-840A (Fig. 4). In this experiment, all three sensors were allowed to stabilize to outdoor pressure, temperature, and humidity conditions $\left(97631.40 \mathrm{~Pa}, 21.85{ }^{\circ} \mathrm{C}\right.$, and $\left.50 \% \mathrm{RH}\right)$, then a hot air source emulated a $40^{\circ} \mathrm{C}$ impulse.

In this second experiment, relative humidity was not controlled as the temperature increased. This uncontrolled method is similar to other experiments found in the literature. The experiment was performed as quickly as possible to avoid contamination due to human exhalation. Besides the experiment speed, the laboratory windows were opened, and a large fan was used to bring outside air into the laboratory constantly. A small mixing fan was also placed near the three sensors (Fig. 4).

The benchtop experiment's time-series data and their corresponding scatter plots are shown in Figs. 5 and 6. In this experiment, the absence of temperature dependence is evident. Even though there is a slight 10 ppm increase in the reported 


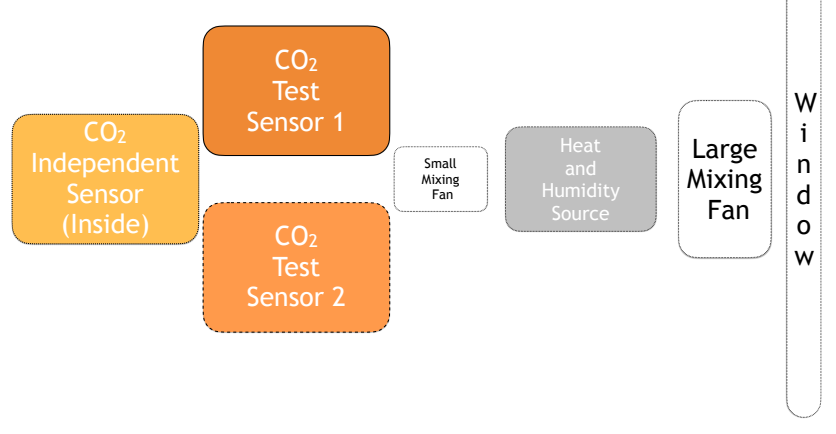

Figure 4. Diagram for the benchtop temperature and relative humidity experiments. All sensors are stabilized to the environment, then exposed to the heat and humidity source, and finally brought back to the environmental conditions by the large mixing fan.

concentration of the test sensors, it occurs a full minute after the temperature is brought back near its original state. This same increase is simultaneously seen on the independent sensor, indicating the increase was caused by an external factor. This conclusion is supported by the weak correlation to temperature and the strong correlation to the independent sensor.

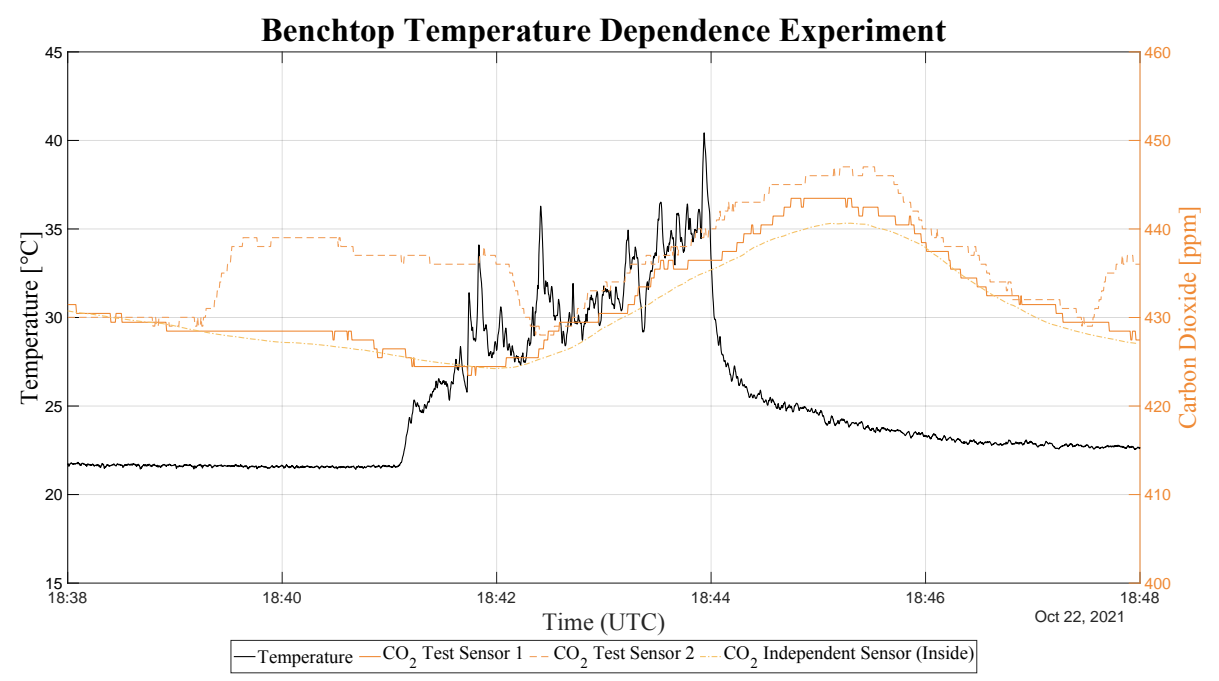

Figure 5. Time series for the benchtop temperature dependence experiment. The solid black curve represents the temperature near the sensors. The three orange curves represent the $\mathrm{CO}_{2}$ concentrations reported by the independent and test sensors. The black (left) and orange (right) $\mathrm{y}$-axes provide the scales for temperature and $\mathrm{CO}_{2}$, respectively. 


\section{Correlation Coefficients for the Benchtop Experiment $\mathrm{CO}_{2}$ Independent Sensor}
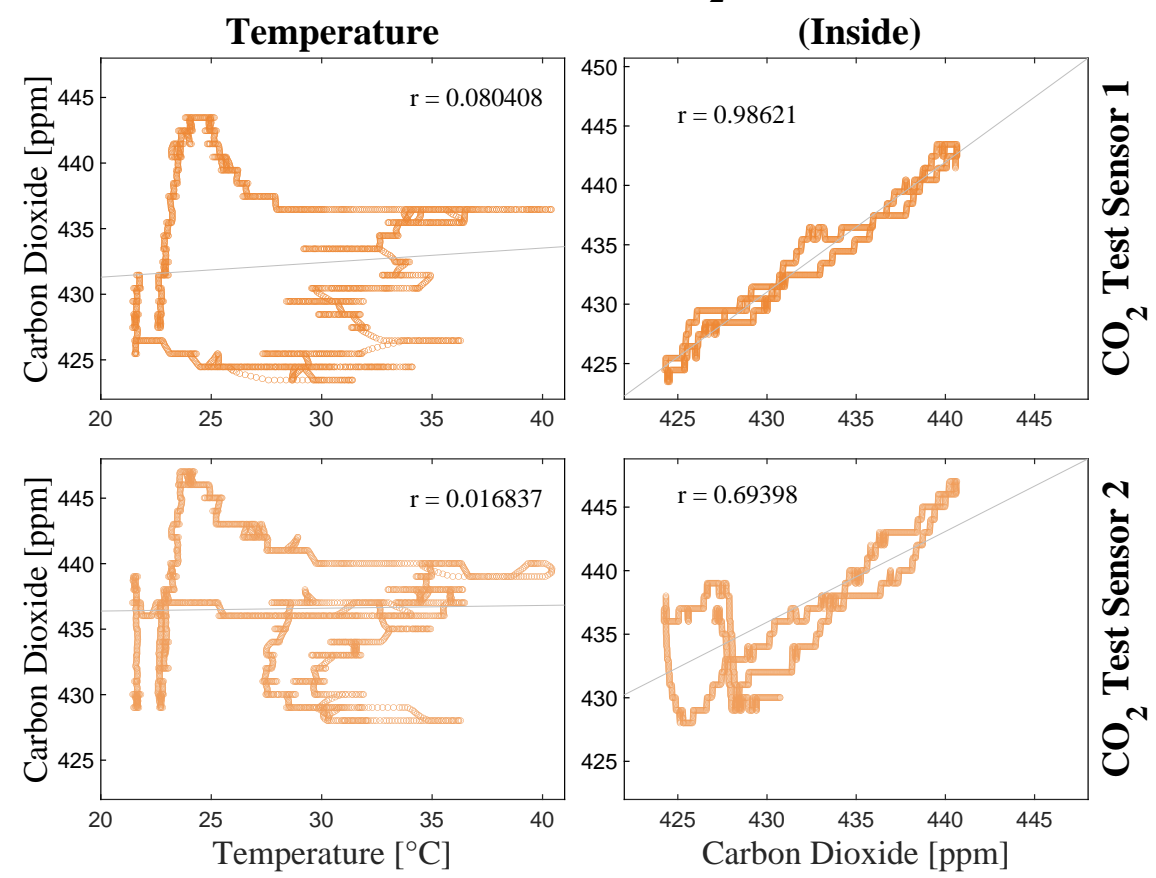

Figure 6. Correlation coefficients for the benchtop temperature dependence experiment. The results are presented as a matrix. The first row shows the correlations for Test Sensor 1. The second row shows the correlations for Test Sensor 2. The first column shows the correlations with temperature, and the second column with the Independent Sensor (inside).

\section{Relative Humidity Dependence}

The relative humidity (RH) dependence experiment performed at the Oklahoma Mesonet Calibration Laboratory was executed under the same experiment setup detailed in section 3 and illustrated by Fig. 1. In this experiment, the chamber produced an $\mathrm{RH}$ variation from $15 \% \mathrm{RH}$ to $95 \% \mathrm{RH}$ at a constant $25{ }^{\circ} \mathrm{C}$. A one-hour dwell period followed each $\mathrm{RH}$ level change. The results for the Mesonet RH dependence experiment are shown here in two formats. The first format, in Fig. 7, shows the timeseries data for the chamber's RH and the reported concentrations for all four $\mathrm{CO}_{2}$ sensors. The second result format, in Fig. 8, shows the scatter plots and correlation coefficients for all six comparisons between the test sensors, test variable, and reference sensors.

Initial analysis of the experiment's results shows a high correlation coefficient between RH and both test sensors. The results also show an increase in $\mathrm{CO}_{2}$ when relative humidity is at or above $75 \% \mathrm{RH}$. This same behavior is observed when the 


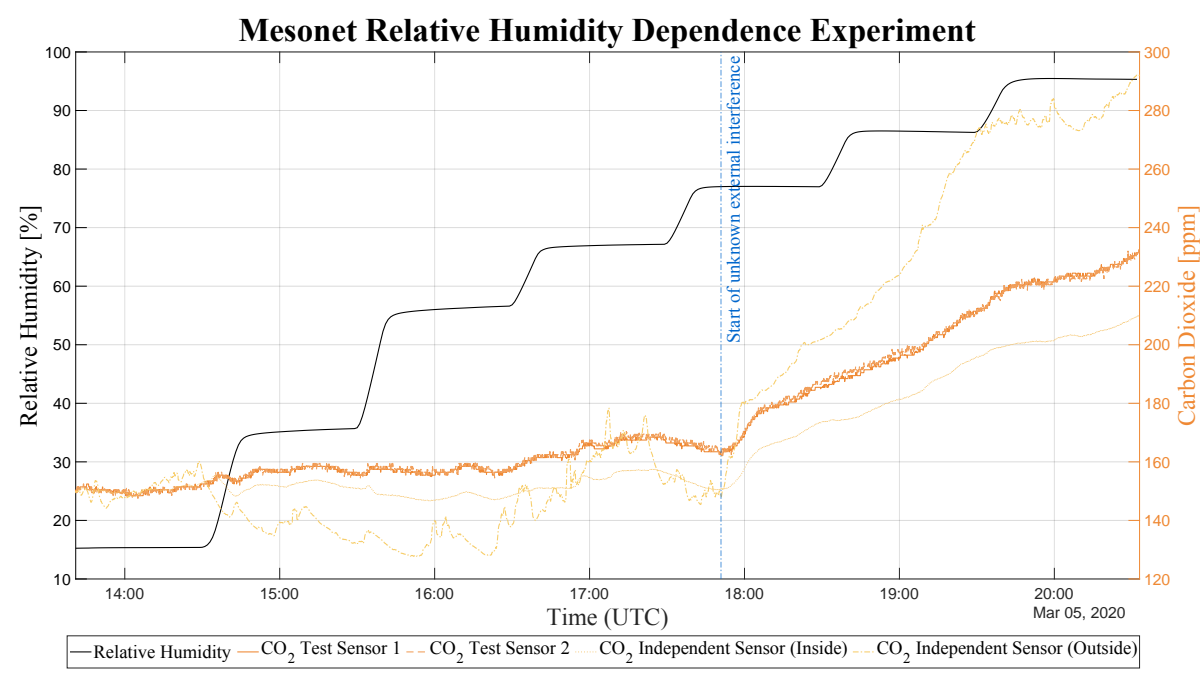

Figure 7. Time-series data for the Mesonet relative humidity dependence experiment. The solid black curve represents the relative humidity inside the chamber. The orange curves represent the $\mathrm{CO}_{2}$ concentrations reported by the independent and test sensors. The black (left) and orange (right) y-axes provide the $\mathrm{RH}$ and $\mathrm{CO}_{2}$ scales, respectively.
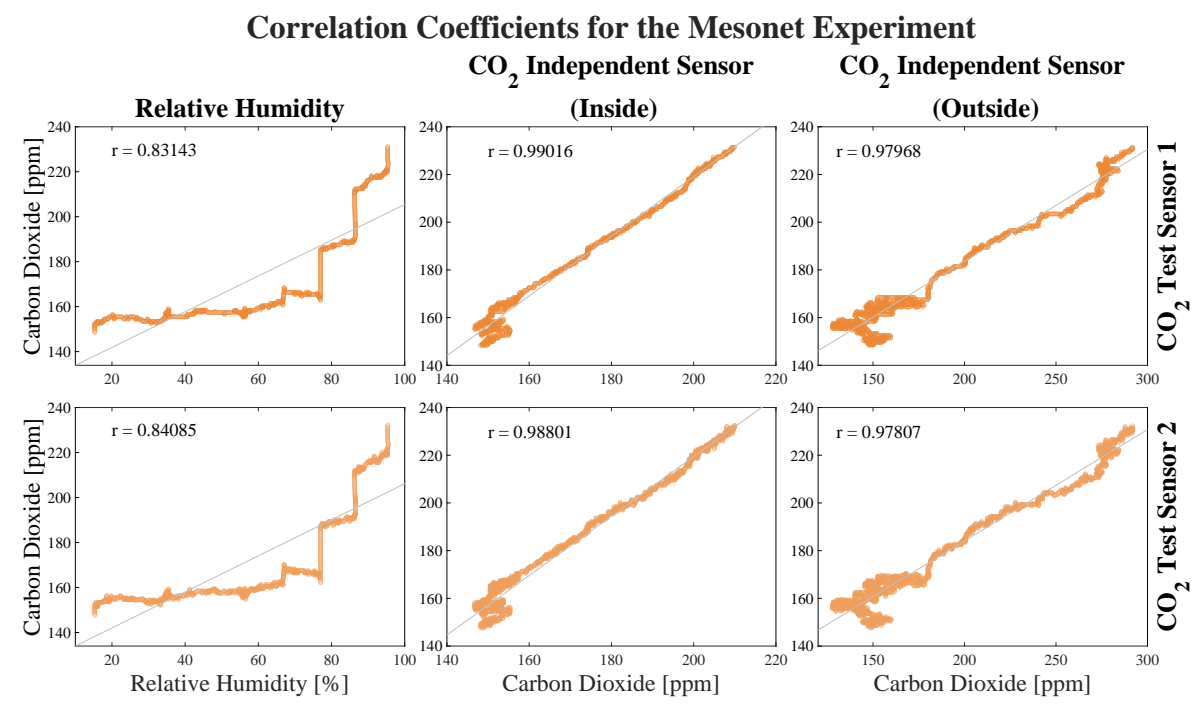

Figure 8. Scatter plots and correlation coefficients for the Mesonet relative humidity dependence experiment. The first row shows the correlations for Test Sensor 1. The second row shows the correlations for Test Sensor 2. The first column shows the correlations with relative humidity, the second column with the Independent Sensor (inside), and the third column with the Independent Sensor (outside).

correlation coefficients are calculated for each RH transition period (summarized in Tab. 2). Further analyzing the results, we note the increase in reported $\mathrm{CO}_{2}$ concentration continues during the entire dwell period for the 75,85 , and $95 \% \mathrm{RH}$ levels. 
Furthermore, similar $\mathrm{CO}_{2}$ increases were also observed on the internal and external independent sensors. This leads us to believe the experiment was again contaminated by an increase in concentration in the laboratory. This hypothesis is supported by a stronger correlation between the test and independent sensors.

To rule out any minor humidity dependence effects obscured by the interference on the Mesonet experiment, a second experiment was performed focused on the RH changes above $75 \% \mathrm{RH}$. This second experiment was performed in the same setup for the low-cost benchtop experiment described in section 3 and illustrated by Fig. 4. The only difference was the substitution of the heat impulse source for a humidity source. In this experiment, all three sensors were allowed to stabilize to outdoor pressure, temperature, and humidity conditions (97644.02 $\mathrm{Pa}, 23.46{ }^{\circ} \mathrm{C}$, and $\left.48.08 \% \mathrm{RH}\right)$, then a source of humid air emulated a $65 \%$ RH step, followed by an $80 \%$ RH step.

The benchtop experiment's time series and the correlation coefficients are shown Fig. 9 and 10. In this experiment, the absence of humidity dependence is evident. Even though there is a $4 \mathrm{ppm}$ increase in the reported concentration of the test sensors, the same increase is simultaneously seen on the independent sensor. This indicates an external factor may have caused the increase. This conclusion is supported by the weak correlation to humidity and the strong correlation to the independent sensor.

Table 2. $\mathrm{CO}_{2}$ correlation coefficients for each test sensor, for each RH change, during the Mesonet relative humidity dependence experiment.

\begin{tabular}{ccc} 
RH [\%] & \multicolumn{2}{c}{ Correlation coefficients } \\
& Sensor 1 & Sensor 2 \\
\hline From 15 to 35 & 0.05 & 0.23 \\
From 35 to 55 & 0.80 & 0.78 \\
From 55 to 65 & 0.96 & 0.91 \\
From 65 to 75 & -0.77 & -0.76 \\
From 75 to 85 & 0.94 & 0.86 \\
From 85 to 95 & 0.96 & 0.95 \\
\hline
\end{tabular}

\section{Pressure Dependence}

The pressure dependence experiment performed at the Oklahoma Mesonet Calibration Laboratory used the Cincinnati SubZero Z16 chamber with a custom gasket-based vacuum and compression system. This custom system was developed by the laboratory's manager, David L. Grimsley. This system produced a pressure variation from 105,000 Pa to 60,000 Pa, in 1,000 Pa increments, under controlled temperature and humidity. Each pressure change was followed by a two-minute dwell period. Even though the temperature and humidity can be controlled, this chamber is not entirely isolated from the external environment. As in previous experiments, this means that changes in $\mathrm{CO}_{2}$ concentration could affect the experiment, and to mitigate contamination, access to the laboratory was limited during the experiment. A reference gas analyzer was placed outside the chamber to detect possible contamination. Fig. 11 illustrates this sensor arrangement. 


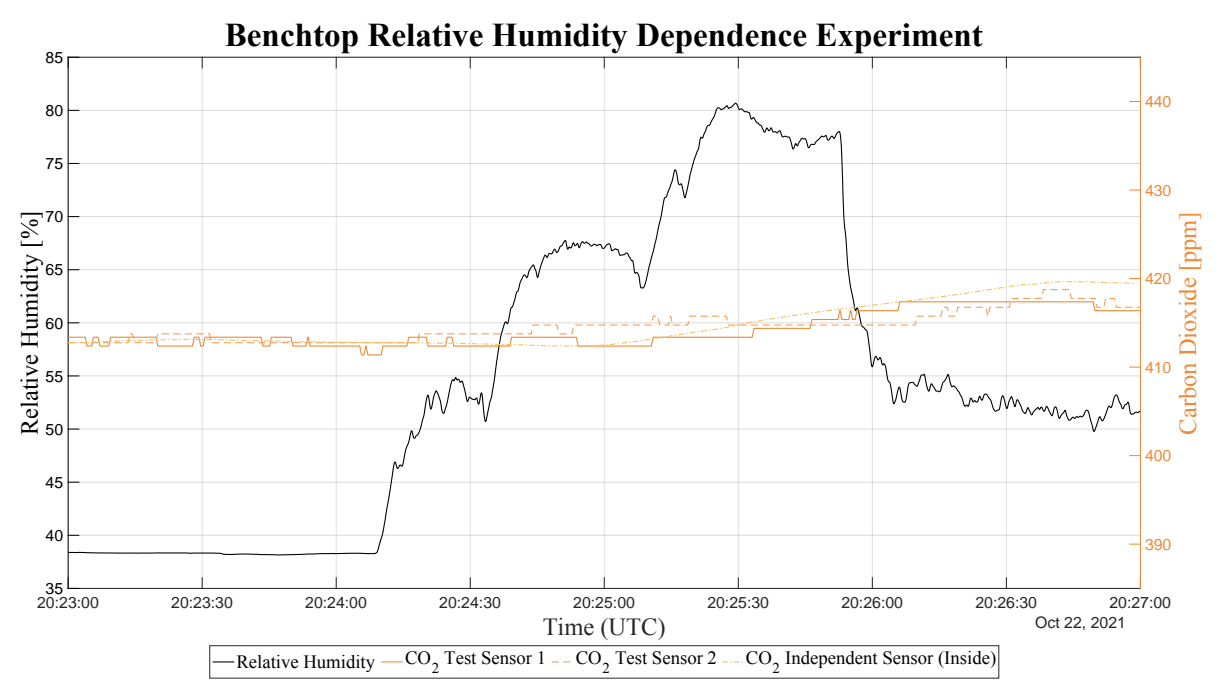

Figure 9. Time-series data for the benchtop relative humidity dependence experiment. The solid black curve represents the relative humidity inside the chamber. The orange curves represent the $\mathrm{CO}_{2}$ concentrations reported by the independent and test sensors. The black (left) and orange (right) $\mathrm{y}$-axes provide the relative humidity and $\mathrm{CO}_{2}$ scales, respectively.

In this experiment, the LI-840A gas analyzer was not placed inside the chamber because its pressure compensation is not rated for this magnitude of pressure change. Instead, it was kept outside the chamber as a reference for the experiment conditions within the laboratory. This external reference was necessary because the pressure system pumps air from the laboratory to increase the pressure from 60,000 Pa back to $105,000 \mathrm{~Pa}$.

This experiment showed an extreme dependence between the $\mathrm{CO}_{2}$ concentration values reported by the test sensors and pressure. A $50 \mathrm{ppm}$ fluctuation outside the chamber produced a small interference during the experiment. However, considering the $250 \mathrm{ppm}$ effect produced by the pressure change, this interference did not change the experiment results (see Fig. 12). This conclusion is corroborated by the correlation coefficients shown in Fig. 13.

\section{1 $\mathrm{CO}_{2}$ Pressure correction}

Within the NDIR sensor literature, the article by Gaynullin et al. (2016) offers an excellent description of the determination of the pressure correction coefficients for the Senseair K30 NDIR $\mathrm{CO}_{2}$ sensor. In their article, Gaynullin et al. (2016) indicates that this coefficient determination procedure needs to be performed for each sensor unit. However, the expertise required to repeat their procedure makes the method inaccessible to most. In this section, we evaluate the feasibility of determining the pressure correction coefficients using a low-cost, readily available vacuum pump and a reference gas analyzer.

The experimental setup for this low-cost procedure (illustrated in Fig. 14) consists of a BACO Engineering 5-Gallon Vacuum Chamber Kit, available at multiple retailers for USD189.99, and the LI-840A gas analyzer. In this setup, the gas analyzer provides the reference concentration for the experiment's initial state. Then, the chamber is closed and isolated from the external environment. Finally, the chamber is depressurized until the top of the emulated UAS-flight is reached. 


\section{Correlation Coefficients for the Benchtop Experiment} $\mathrm{CO}_{2}$ Independent Sensor
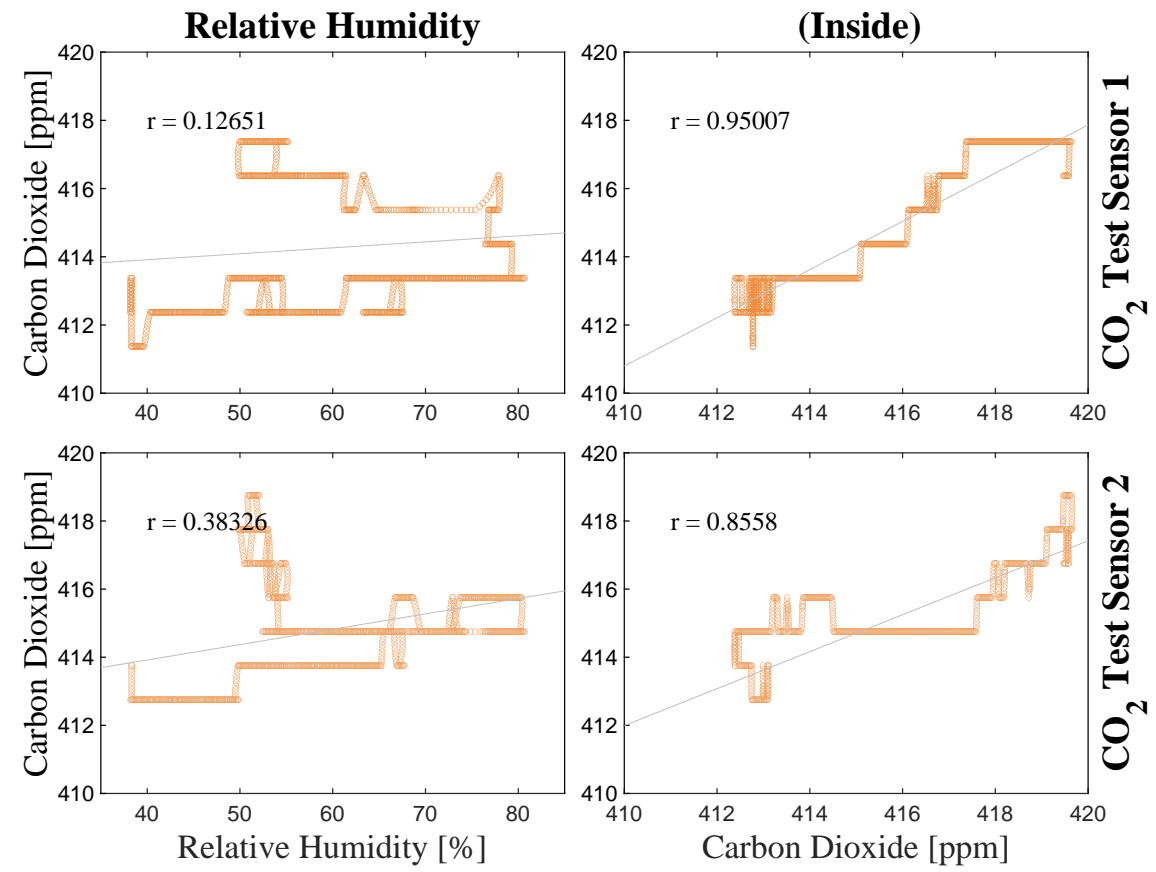

Figure 10. Scatter plots and correlation coefficients for the benchtop relative humidity dependence experiment. The results are presented as a matrix. The first row shows the correlations for Test Sensor 1. The second row shows the correlations for Test Sensor 2. The first column shows the correlations with relative humidity and the second column with the Independent Sensor (inside).

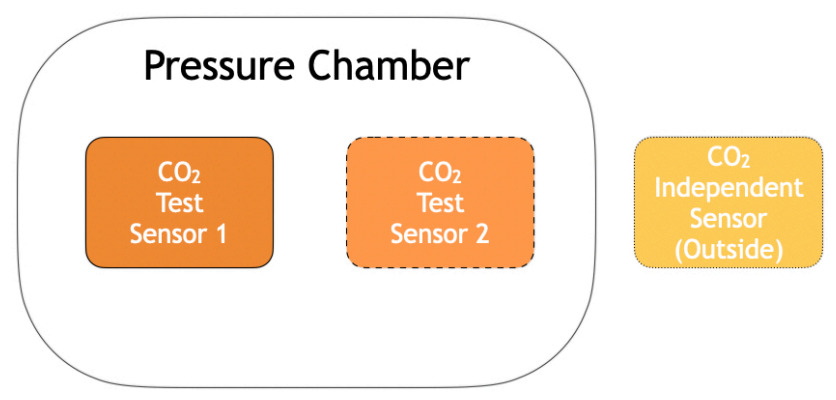

Figure 11. Diagram for the Mesonet pressure experiment. Two test sensors were placed inside the chamber and a reference sensor was place outside to indicate possible contamination. 


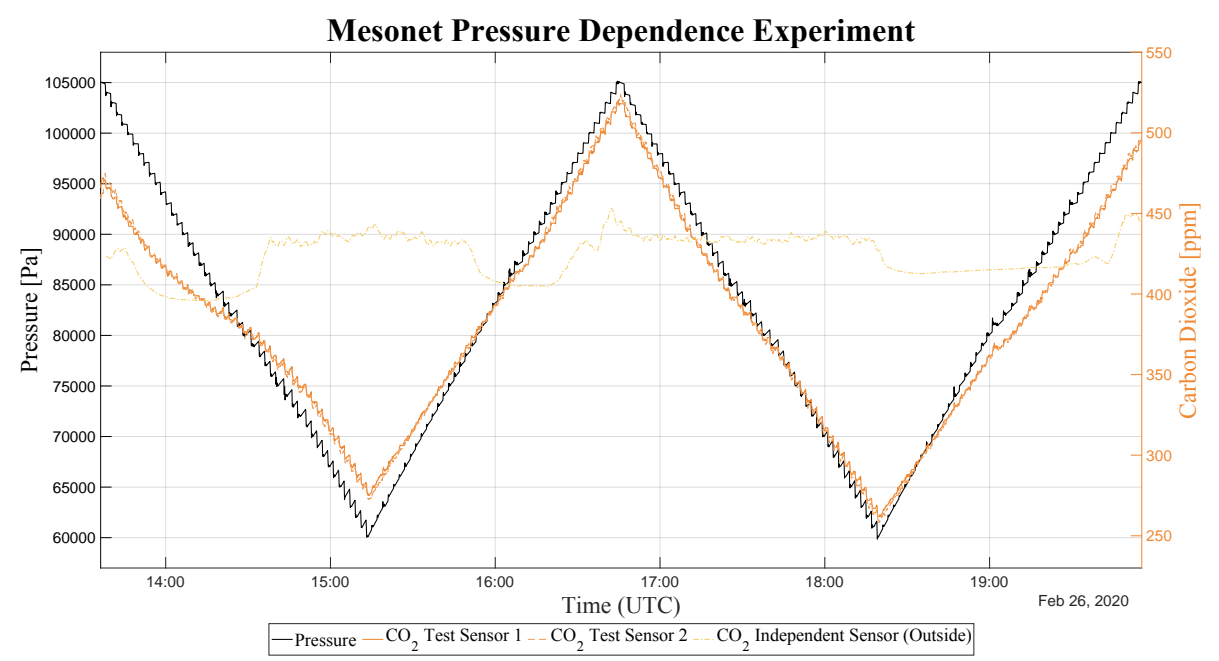

Figure 12. Time-series data for the Mesonet pressure dependence experiment. The solid black curve represents the pressure inside the chamber. The orange curves represent the $\mathrm{CO}_{2}$ concentrations reported by the independent and test sensors. The black (left) and orange (right) $\mathrm{y}$-axes provide the scales for pressure and $\mathrm{CO}_{2}$, respectively.

Because this method uses the ambient $\mathrm{CO}_{2}$ concentration and pressure as its initial state, the correction needs to be based on the variation magnitude from the initial state. This method implies that the relationship between the changes in pressure and $\mathrm{CO}_{2}$ is independent from the initial conditions. This assumption is supported by the results of the Mesonet pressure dependence experiment that showed similar behavior for pressures higher and lower than sea level pressure. Nonetheless, to validate this assumption, the method was developed using two learning cases and then tested on two different test cases. Since each test case is performed with two test sensors, the assumption was evaluated four different times.

As shown in Fig. 15, all four cases used for development and evaluation have different initial pressures and $\mathrm{CO}_{2}$ concentrations. However, all initial pressures are lower than sea level pressure because the experiments were performed in Oklahoma (approximately $360 \mathrm{~m}$ above sea level). All cases emulate a typical UAS-based $\mathrm{CO}_{2}$ vertical profile, where there is a dwell period (in this case, 1.5 minutes) to ensure samples from the previous altitude are discarded from the system after a change in altitude.

The correction coefficients for each of the two test sensors were determined using the cubic equation fitting method from Gaynullin et al. (2016) and the data from the two cases labeled as "Learn". The results from these experiments can be seen in Fig. 16, where the time-series data for the reference, original, and corrected concentrations (for both test sensors) are plotted together for comparison. The results demonstrate four instances where the low-cost coefficient determination method successfully produced errors smaller than $\pm 2.5 \mathrm{ppm}$. This result is even more impressive considering the data represents emulated flights up to 5,200 ft above ground level in Oklahoma or 6,500 ft above sea level. 


\section{Correlation Coefficients for the Mesonet Experiment $\mathrm{CO}_{2}$ Independent Sensor}
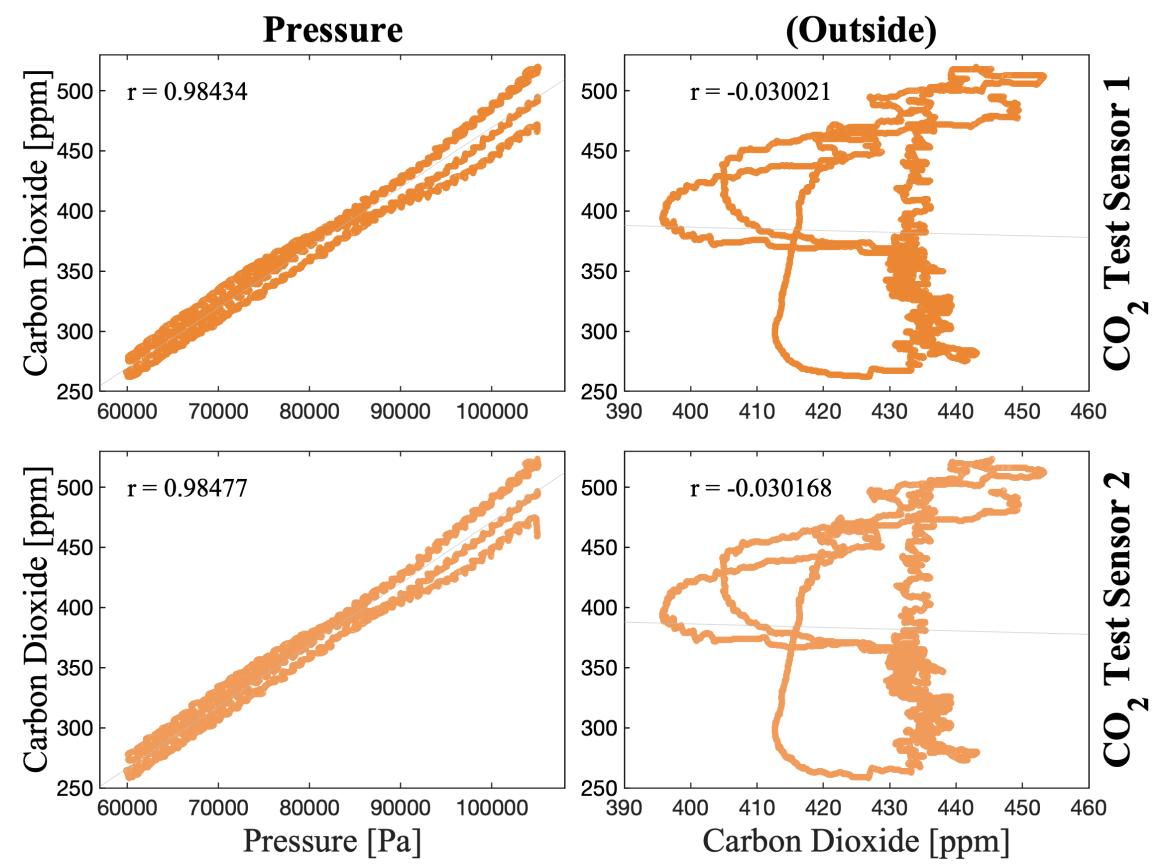

Figure 13. Scatter plots and correlation coefficients for the Mesonet pressure dependence experiment. The first row shows the correlations for Test Sensor 1. The second row shows the correlations for Test Sensor 2. The first column shows the correlations with pressure and the second column with the Independent Sensor (outside).

\section{Time Response to Pressure}

While analyzing the data for the pressure correction experiment, a delay in $\mathrm{CO}_{2}$ concentration change due to pressure change was noticed. No mention of such affect was found in all the literature reviewed for this article. Therefore, the pressure correction experiment setup (detailed in section 5.1) was used again to further investigate the matter.

Using four distinct patterns of pressure variation, shown in Fig. 17, the existence of a time-response to pressure was confirmed. This effect can be visualized in the fourth case, where the sharp pressure change produces an exponential response in $\mathrm{CO}_{2}$. Because the pressure chamber is completely isolated from the external environment, we can affirm this delay is independent of the effects of the sensor's time response to actual changes in $\mathrm{CO}_{2}$ concentration.

Perhaps the common practice of using custom sensor housing and controlled airflow for UAS-based gas sampling (e.g., B. H. de Azevedo, 2020) is the reason why this effect does not appear in the literature. When employing these two techniques, 


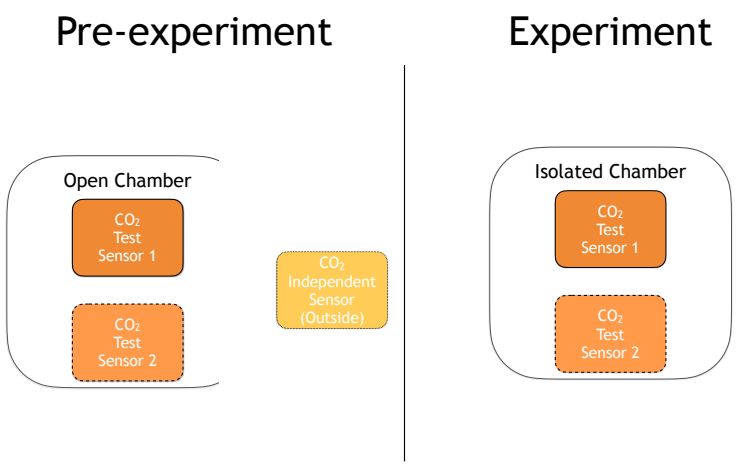

Figure 14. Diagram for the benchtop pressure correction experiment. Chamber and sensors stabilize to environment conditions (preexperiment). Then, the chamber's isolation maintains the initial $\mathrm{CO}_{2}$ concentration while pressure changes.
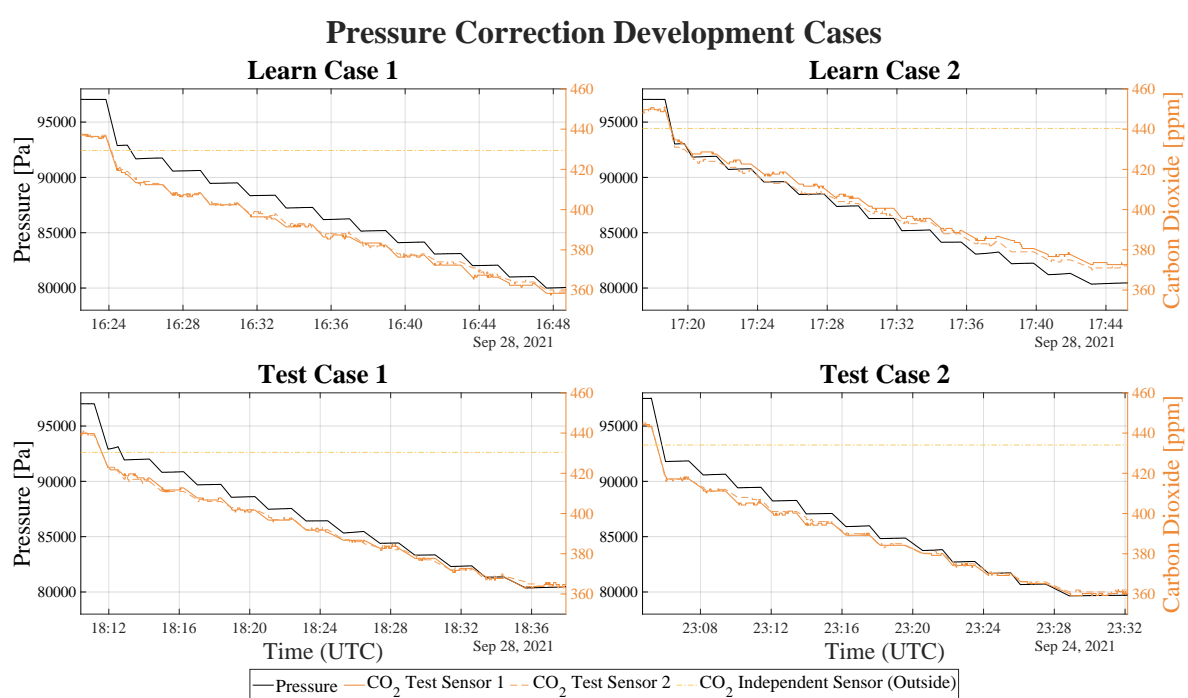

Figure 15. Dataset for development and validation of the pressure correction coefficient determination method. The first row data was used to determine the coefficients for each test sensor, and the second row data was used to evaluate the performance of the coefficients. The solid black curve represents the pressure inside the chamber. The orange curves represent the $\mathrm{CO}_{2}$ concentrations reported by the independent and test sensors. The black (left) and orange (right) y-axes provide the scales for pressure and $\mathrm{CO}_{2}$, respectively.

215 a volume bigger than NDIR sensor's optical chamber is created. Therefore, when the aircraft changes altitude, the first samples at the new altitude need to be discarded. This common practice avoids errors such as gradient blurring. Albeit, unintentionally, 

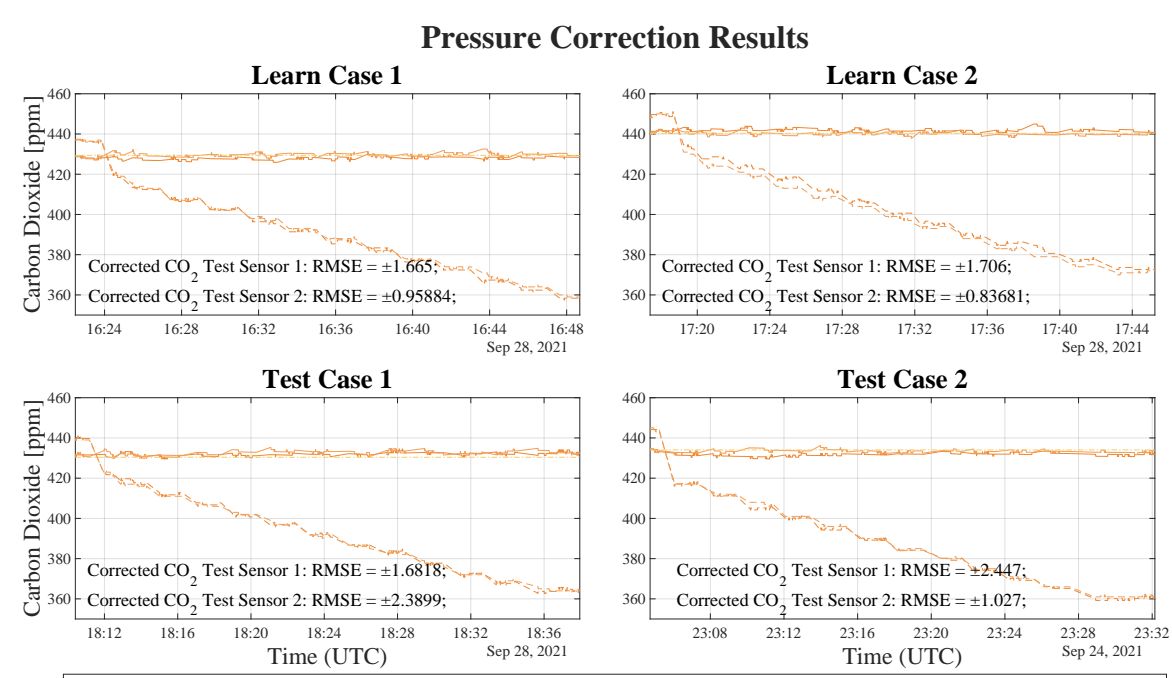

$\mathrm{CO}_{2}$ Test Sensor 1 - $\mathrm{CO}_{2}$ Test Sensor 2 - Corrected CO $\mathrm{CO}_{2}$ Test Sensor 1 - Corrected $\mathrm{CO}_{2}$ Test Sensor $2 \ldots \mathrm{CO}_{2}$ Independent Sensor (Outside)

Figure 16. Results from the low-cost coefficient determination experiment. The dashed lines represent the original data, and the solid lines represent the corrected data.

this practice would also mitigate this pressure time response error from the pressure correction algorithm. Nonetheless, we used the data from the two test cases for the pressure correction to evaluate if a pressure time response correction could be developed.

The error correction was performed in two parts. First, we used an exponential correction, also known as an e-folding correction, following the time response modeling from Houston and Keeler (2018) and Miloshevich et al. (2004). The time constant for the exponential correction was estimated from the data in development cases 3 and 4 . Finally, we applied a constant time shift on the data. The shift constant was estimated from development cases 1 and 2 . The results for our correction attempts are shown in Fig. 18 and 19.

To evaluate the impact of the correction attempt, an idealized signal was created using the timestamps of the pressure changes and average $\mathrm{CO}_{2}$ concentration for each pressure level. The proposed correction method was able to improve the mean absolute error (MAE) for both sensor units, when compared to the idealized signal. MAE for Sensor 1 improved from 0.9806 to $0.6633 \mathrm{ppm}$ and Sensor 2 improved from 0.8702 to $0.5940 \mathrm{ppm}$. The improvements are even more expressive when we analyze the maximum absolute error (MxAE). Sensor 1 improved from $M x A E=12.965$ to $5.3024 \mathrm{ppm}$ and Sensor 2 improved from $M x A E=11.533$ to $4.4393 \mathrm{ppm}$.

Unfortunately, the attempted correction was not as effective on the gradual pressure changes. For example, during the period from 18:26 to 18:32, shown on the time series for Sensor 2 on the Test Case 1 (Fig. 18). However, as mentioned before, this error will not appear in most applications, and it can be mitigated by discarding initial samples for each altitude. For those who this time response may be an issue, we recommend repeating these experiments on a better quality chamber. One capable of 


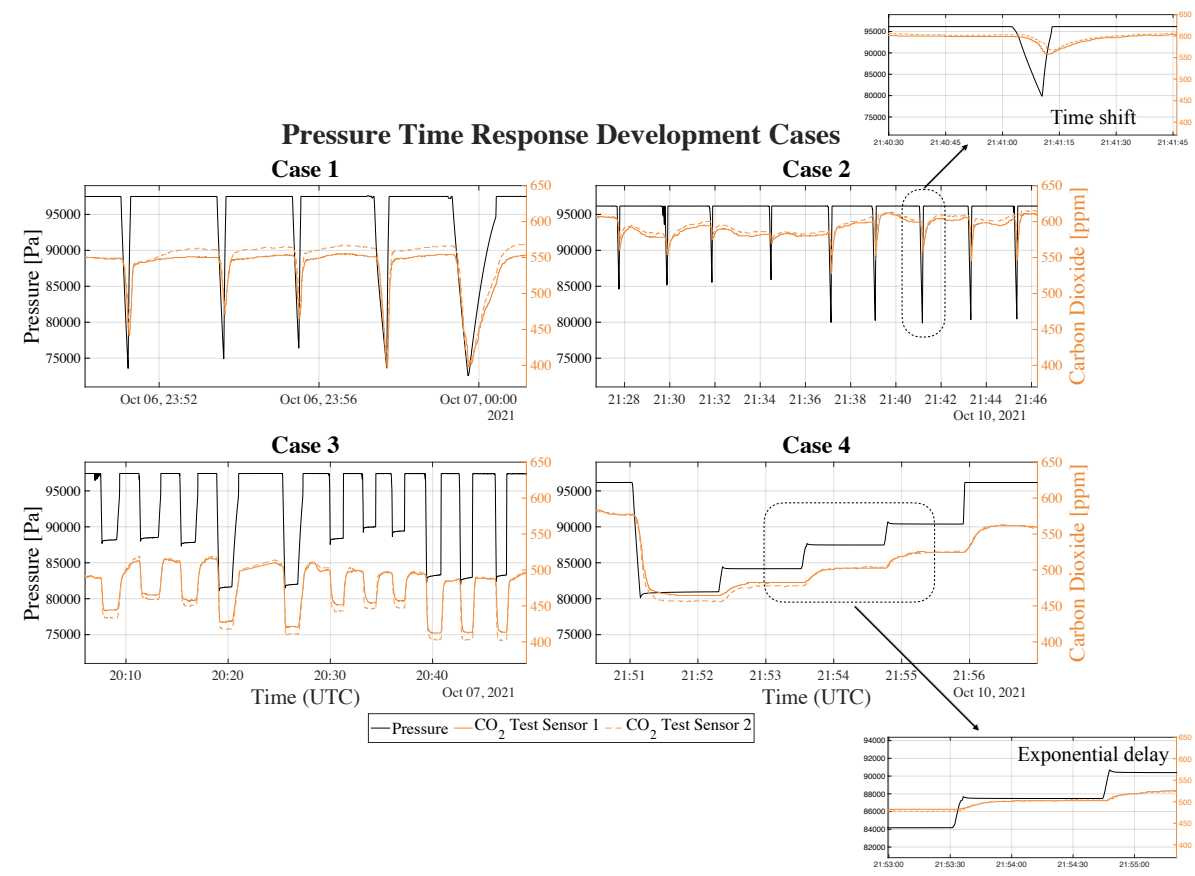

Figure 17. Development data for investigation of the pressure time-response. Cases 2 and 4 highlight the time shift and exponential delay. For all plots, the solid black series represents the pressure inside the chamber. The two orange series represent the $\mathrm{CO}_{2}$ concentrations reported by the test sensors. The black (left) and orange (right) y-axes provide the scales for pressure and $\mathrm{CO}_{2}$, respectively.

producing smaller and better-defined pressure changes. The solenoid-base control for the low-cost BACO Engineering 5-Gallon Vacuum Chamber Kit did not produce data with enough quality to investigate the matter further.

\section{Conclusions}

In this article, we validated previous results in the literature and produced new results that support the general robustness of low-cost NDIR sensors. More importantly, we presented a low-cost benchtop correction procedure to considerably improve the accuracy of $\mathrm{CO}_{2}$ measurements to be within $\pm 2.5 \mathrm{ppm}$. These findings support the use of low-cost NDIR sensors for UAS-based atmospheric measurements as a complementary in-situ tool for many scientific applications.

This article also produced important results regarding the isolated impact of each of the three variables tested. Even though the results in this article did not support a direct dependence between the reported concentrations, temperature, and humidity, minor impacts from these variables cannot be ruled out. Future characterization and validation work should investigate a lowcost setup using NIST traceable canisters with known concentration to control $\mathrm{CO}_{2}$ conditions during the experiments.

In the particular case of temperature dependence, we also recommend expanding the isolated experiments done in this article to cover low temperatures. The test sensors used here, the $\mathrm{K} 30$, are rated for operations from $0{ }^{\circ} \mathrm{C}$ to $50{ }^{\circ} \mathrm{C}$, but other sensors 


\section{Pressure Time Response Correction Test Case 1}
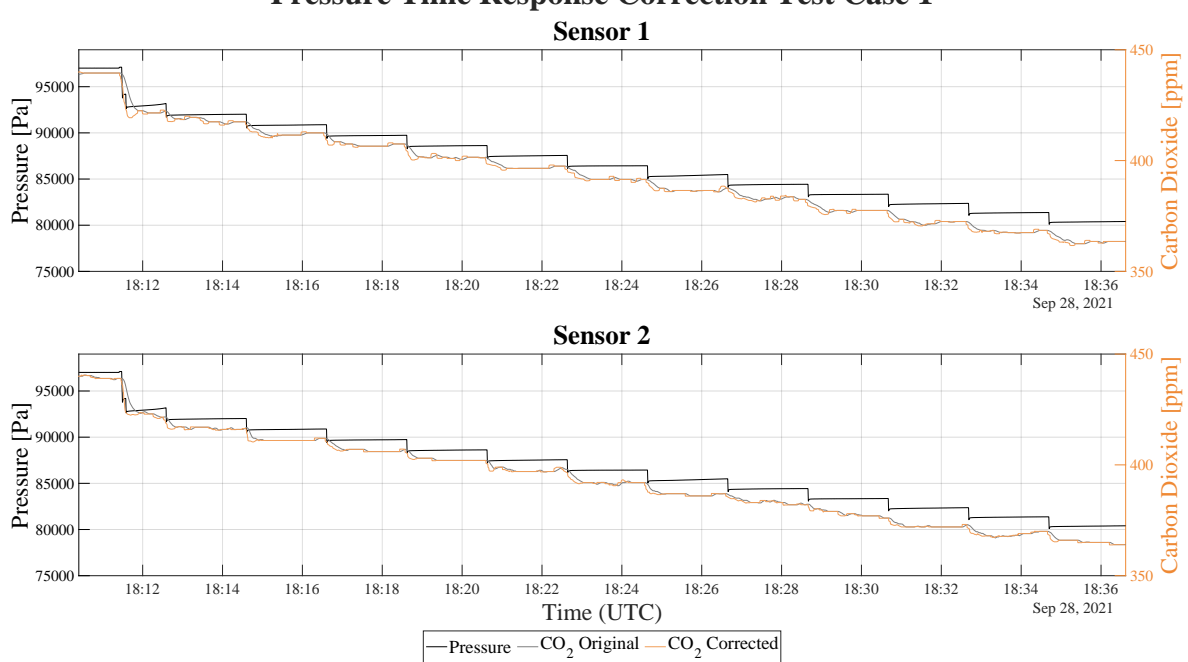

Figure 18. Correction Results for Test Case 1 for pressure time response. The solid black curve represents the pressure inside the chamber. The grey and orange curves represent the original and corrected $\mathrm{CO}_{2}$ concentrations reported by the test sensor. The black (left) and orange (right) $\mathrm{y}$-axes provide the scales for pressure and $\mathrm{CO}_{2}$, respectively.

Pressure Time Response Correction Test Case 2
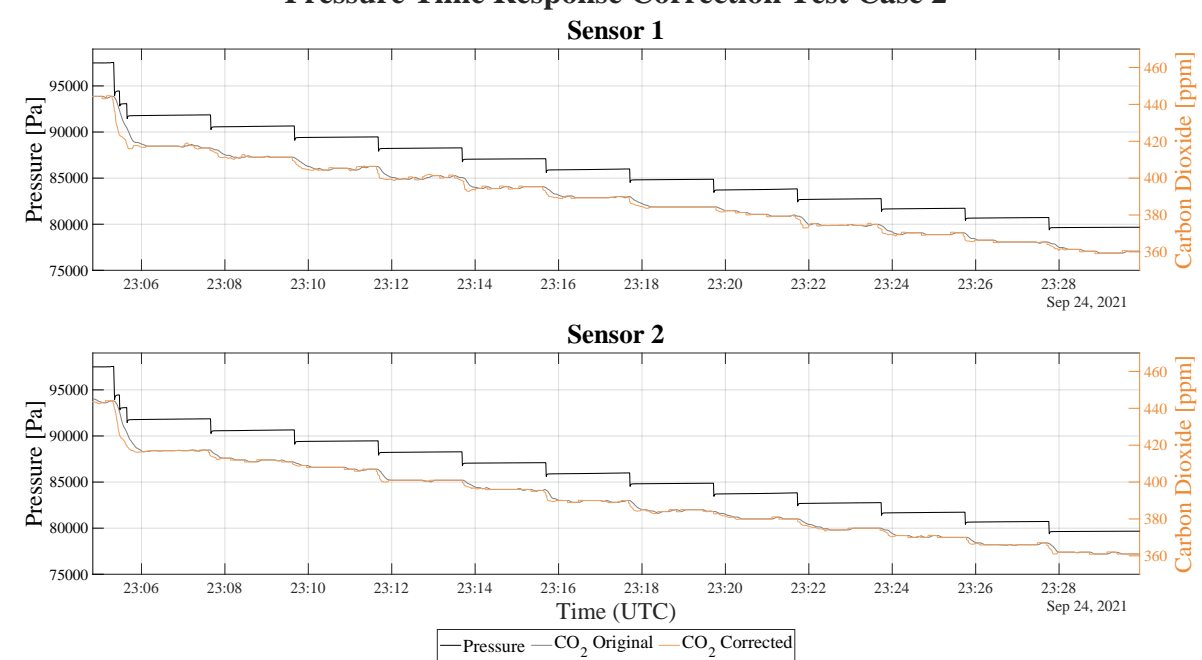

Figure 19. Correction Results for Test Case 2 for pressure time response. The solid black curve represents the pressure inside the chamber. The grey and orange curves represent the original and corrected $\mathrm{CO}_{2}$ concentrations reported by the test sensor. The black (left) and orange (right) $\mathrm{y}$-axes provide the scales for pressure and $\mathrm{CO}_{2}$, respectively. 
within the low-cost NDIR category have broader ranges. Therefore, continuing to expand the test range and repeating these experiments with other low-cost NDIR sensor models will increase accuracy and trust in low-cost UAS-based measurements done with them.

It is also important to note that the statements from Gaynullin et al. (2016), regarding the need for a distinct set of correction coefficients for each sensor were verified in this study. This requirement is also supported by Martin et al. (2017), who found that a generalized set of coefficients could make the accuracy worse than uncorrected accuracy.

In our concluding remarks, we would like to emphasize the importance of sensor placement, sensor housing design, airflow control to successful UAS-based measurements. Furthermore, the characterization of UAS-based systems should take into account the potential contamination introduced by the aircraft and its mode of operation (e.g., vertical profile, transects, hover, and other flight patterns). Finally, any system used to support long-term research or forecast operations should also account for temporal drift and sensor decay.

\section{Appendix A}

Table A1. Examples of low-cost NDIR sensors

\begin{tabular}{lccccccc}
\hline Manufacturer & Vaisala & Senseair & $\begin{array}{c}\text { ELT } \\
\text { Co. }\end{array}$ & $\begin{array}{c}\text { Korea } \\
\text { Digital Co. } \\
\text { Model }\end{array}$ & GMM222C & K30 & Sensing \\
S100 & AN100 & T6615 & $\begin{array}{c}\text { Amphenol } \\
\text { Advanced Sensors } \\
\text { T6613 }\end{array}$ & Cozir \\
\hline Measurement range [ppm] & $0-2000$ & $0-5000$ & $0-10000$ & $0-5000$ & $0-10000$ & $0-2000$ & $0-10000$ \\
Accuracy [ppm] & \pm 30 & \pm 30 & \pm 50 & \pm 200 & \pm 75 & \pm 30 & \pm 50 \\
Weight [g] & 220 & 17 & 10 & 29 & 17 & - & 20 \\
Cost [USD] & - & 95.00 & - & - & 104.81 & 99.72 & 109.00 \\
\hline
\end{tabular}

Sources: senseair.com, eltsensor.co.kr, farnell.com/datasheets/484016.pdf, amphenol-sensors.com; co2meter.com, Al-Hajjaji et al. (2017), and Yasuda et al. (2012). 
https://doi.org/10.5194/amt-2022-50

Atmospheric

Preprint. Discussion started: 25 February 2022

(c) Author(s) 2022. CC BY 4.0 License.

\section{Appendix B}

Table B1. Literature search arrangements

\begin{tabular}{|c|c|}
\hline Search string & Results \\
\hline$+\mathrm{CO} 2$ +unmanned +aerial & 11,300 \\
\hline +CO2 + unmanned +aerial +(GMM222C OR S100 OR AN100 OR T6615) -(K30 OR K-30 OR “K 30”) & 6 \\
\hline +Carbon +dioxide +unmanned +aerial & 10,500 \\
\hline +Carbon +dioxide +unmanned +aerial +(GMM222C OR S100 OR AN100 OR T6615) -(K30 OR K-30 OR “K 30”) & 3 \\
\hline +Carbon +dioxide +remotely +piloted +aircraft & 1520 \\
\hline +Carbon +dioxide +remotely +piloted +aircraft +(K30 OR K-30 OR “K 30”) & 7 \\
\hline
\end{tabular}


https://doi.org/10.5194/amt-2022-50

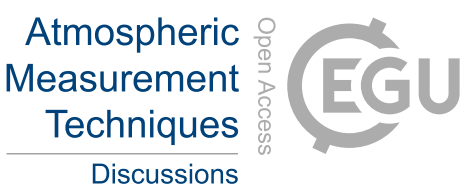

Preprint. Discussion started: 25 February 2022

(c) Author(s) 2022. CC BY 4.0 License.

(c) (1)

Discussions

Author contributions. This study was conceptualized by GBHA and DS. The methodology was designed by GBHA, DS. The Mesonet experiments were designed by GBHA and CAF. The Benchtop experiments were designed by GBHA, DS, and BD. The formal analysis and post-processing of the data were carried out by GBHA under the supervision of DS. Supporting software was developed by GBHA, DS, and BD. The original draft was written by GBHA and reviewed and edited by GBHA, DS, BD, and CAF.

Competing interests. The authors declare that they have no conflicts of interest.

Acknowledgements. The authors would like to recognize the efforts of David L. Grimsley, the manager of the Oklahoma Mesonet Calibration Laboratory, for his technical support during the Mesonet chamber experiments. The authors would like thank Dr.Jacob from the Unmanned Systems Research Institute at the Oklahoma State University, for providing the LI-COR LI-820 reference gas analyzer used in the Mesonet chamber experiments. This study was supported in part by the Vice President for Research and Partnerships (VPRP) of the University of Oklahoma OU. 


\section{References}

Al-Hajjaji, K., Ezzin, M., Khamdan, H., Hassani, A. E., and Zorba, N.: Design, development and evaluation of a UAV to study air quality in Qatar, arXiv preprint arXiv:1709.05628, 2017.

Ashraf, S., Mattsson, C. G., Thungström, G., Gaynullin, B., and Rödjegård, H.: Evaluation of a $\mathrm{CO}_{2}$ sensitive thermopile with an integrated multilayered infrared absorber by using a long path length NDIR platform, in: 2018 IEEE International Instrumentation and Measurement Technology Conference (I2MTC), pp. 1-6, https://doi.org/10.1109/I2MTC.2018.8409758, 2018.

B. H. de Azevedo, G.: Spatially-temporally resolved sampling system for carbon dioxide concentration in the atmospheric boundary layer : a low-cost UAS approach., 2020.

Cartier, K. M. S.: Human activity outpaces volcanoes, asteroids in releasing deep carbon, Eos, 100, 2019.

Chen, S., Yamaguchi, T., and Watanabe, K.: A simple, low-cost non-dispersive infrared $\mathrm{CO}_{2}$ monitor, in: 2nd ISA/IEEE Sensors for Industry Conference, pp. 107-110, https://doi.org/10.1109/SFICON.2002.1159816, 2002.

Gaynullin, B., Bryzgalov, M., Hummelgård, C., and Rödjegard, H.: A practical solution for accurate studies of NDIR gas sensor pressure dependence. Lab test bench, software and calculation algorithm, in: 2016 IEEE SENSORS, pp. 1-3, https://doi.org/10.1109/ICSENS.2016.7808828, 2016.

Gibson, D. and MacGregor, C.: A Novel Solid State Non-Dispersive Infrared $\mathrm{CO}_{2}$ Gas Sensor Compatible with Wireless and Portable Deployment, Sensors, 13, 7079-7103, 2013.

Houston, A. L. and Keeler, J. M.: The Impact of Sensor Response and Airspeed on the Representation of the Convective Boundary Layer and Airmass Boundaries by Small Unmanned Aircraft Systems, Journal of Atmospheric and Oceanic Technology, 35, 1687 - 1699, https://doi.org/10.1175/JTECH-D-18-0019.1, 2018.

Kiefer, C. M., Clements, C. B., and Potter, B. E.: Application of a Mini Unmanned Aircraft System for In Situ Monitoring of Fire Plume Thermodynamic Properties, Journal of Atmospheric and Oceanic Technology, 29, 309-315, https://doi.org/10.1175/JTECH-D-11-00112.1, 2012.

Kunz, M., Lavric, J., Gerbig, C., Tans, P., Neff, D., Hummelgärd, C., Martin, H., Rödjegård, H., Wrenger, B., and Heimann, M.: COCAP: A carbon dioxide analyser for small unmanned aircraft systems, Atmos. Meas. Tech., 11, 1833-1849, https://doi.org/10.5194/amt-11-18332018, 2018.

Martin, C. R., Zeng, N., Karion, A., Dickerson, R. R., Ren, X., Turpie, B. N., and Weber, K. J.: Evaluation and environmental correction of ambient $\mathrm{CO}_{2}$ measurements from a low-cost NDIR sensor, Atmospheric Measurement Techniques, 10, 2383-2395, https://doi.org/10.5194/amt-10-2383-2017, 2017.

McPherson, R. A., Fiebrich, C. A., Crawford, K. C., Kilby, J. R., Grimsley, D. L., Martinez, J. E., Basara, J. B., Illston, B. G., Morris, D. A., Kloesel, K. A., Melvin, A. D., Shrivastava, H., Wolfinbarger, J. M., Bostic, J. P., Demko, D. B., Elliott, R. L., Stadler, S. J., Carlson, J. D., and Sutherland, A. J.: Statewide Monitoring of the Mesoscale Environment: A Technical Update on the Oklahoma Mesonet, Journal of Atmospheric and Oceanic Technology, 24, 301-321, https://doi.org/10.1175/JTECH1976.1, 2007.

Miloshevich, L. M., Paukkunen, A., Vömel, H., and Oltmans, S. J.: Development and Validation of a Time-Lag Correction for Vaisala Radiosonde Humidity Measurements, Journal of Atmospheric and Oceanic Technology, 21, 1305 - 1327, https://doi.org/10.1175/15200426(2004)021<1305:DAVOAT>2.0.CO;2, 2004.

Mitchell, T., Kidd, J., and Jacob, J. D.: Wildfire Plume Tracking and Dynamics Using UAS with In-Situ CO 2 Measurements, AIAA SciTech Forum, 4, 2016. 
Mizoguchi, Y. and Ohtani, Y.: Comparison of response characteristics of small CO2 sensors and an improved method based on the sensor response, Journal of Agricultural Meteorology (Japan), 2005.

310 Nelson, K. N., Boehmler, J. M., Khlystov, A. Y., Moosmuller, H., Samburova, V., Bhattarai, C., Wilcox, E. M., and Watts, A. C.: A Multipollutant Smoke Emissions Sensing and Sampling Instrument Package for Unmanned Aircraft Systems: Development and Testing, Fire, 2, 32, 2019.

Pandey, S. K. and Kim, K.-H.: The Relative Performance of NDIR-based Sensors in the Near Real-time Analysis of $\mathrm{CO}_{2}$ in Air, Sensors, 7 , 1683-1696, https://doi.org/10.3390/s7091683, 2007.

315 Piedrahita, R., Xiang, Y., Masson, N., Ortega, J., Collier, A., Jiang, Y., Li, K., Dick, R. P., Lv, Q., Hannigan, M., and Shang, L.: The next generation of low-cost personal air quality sensors for quantitative exposure monitoring, Atmospheric Measurement Techniques, 7 , 3325-3336, https://doi.org/10.5194/amt-7-3325-2014, 2014.

Stephens, B. B., Miles, N. L., Richardson, S. J., Watt, A. S., and Davis, K. J.: Atmospheric $\mathrm{CO}_{2}$ monitoring with single-cell NDIR-based analyzers, Atmospheric Measurement Techniques, 4, 2737-2748, https://doi.org/10.5194/amt-4-2737-2011, 2011.

Villa, T. F., Gonzalez, F., Miljievic, B., Ristovski, Z. D., and Morawska, L.: An Overview of Small Unmanned Aerial Vehicles for Air Quality Measurements: Present Applications and Future Prospectives, Sensors, 16, https://doi.org/10.3390/s16071072, 2016.

Watai, T., Machida, T., Ishizaki, N., and Inoue, G.: A Lightweight Observation System for Atmospheric Carbon Dioxide Concentration Using a Small Unmanned Aerial Vehicle, Journal of Atmospheric and Oceanic Technology, 23, 700 - 710, https://doi.org/10.1175/JTECH1866.1, 2006.

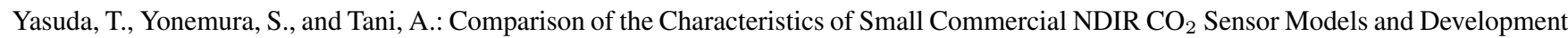
of a Portable $\mathrm{CO}_{2}$ Measurement Device, Sensors, 12, 3641-3655, https://doi.org/10.3390/s120303641, 2012.

Yasuda, Y., Ohtani, Y., Mizoguchi, Y., Nakamura, T., and Miyahara, H.: Development of a $\mathrm{CO}_{2}$ gas analyzer for monitoring soil $\mathrm{CO}_{2}$ concentrations, Journal of forest research, 13, 320, 2008 